CASE REPORT

\title{
Association of idiopathic hepatic sinusoidal dilatation with the immunological features of the antiphospholipid syndrome
}

\author{
D Saadoun, D Cazals-Hatem, M-H Denninger, L Boudaoud, B-N Pham, V Mallet, B Condat, \\ J Brière, D Valla
}

\begin{abstract}
Background: Isolated sinusoidal dilatation is an uncommon hepatic lesion and the cause is largely unknown.

Objective: To investigate whether prothrombotic disorders or perisinusoidal cell changes could be involved in pure idiopathic hepatic sinusoidal dilatation (HSD).

Methods: Evaluation for associated conditions, prothrombotic disorders, and studies of hepatic perisinusoidal cell activation in consecutive patients, seen between 1993 and 2002 , with isolated sinusoidal dilatation unrelated to oufflow block, sinusoidal infiltration, or hepatic granulomas.

Results: Among 11 patients, associated conditions were prothrombotic disorders $(n=5)$ and oral contraceptive use $(n=3)$. Prothrombotic disorders were polycythemia vera $(n=1)$ and anticardiolipin antibodies combined with lupus anticoagulant $(n=4)$. No genetic thrombophilia factor was found. Of four patients with lupus anticoagulant, three had antinuclear factors and high serum levels of anticardiolipin antibodies at repeated testing. There was no evidence of intrahepatic or extrahepatic thrombosis in any of the patients. Sinusoidal dilatation was marked in six of 11 patients (54\%), including two patients with antiphospholipid antibodies. Activated perisinusoidal cells were only found around markedly dilated sinusoids.

Conclusion: Idiopathic pure HSD is frequently associated with the immunological features of the antiphospholipid syndrome. Therefore, finding pure HSD in a liver biopsy specimen should prompt the search for antiphospholipid antibodies.
\end{abstract}

$\mathrm{H}$ epatic sinusoidal dilatation (HSD) is characterised by widening of hepatic capillaries which may involve the entire lobule or predominate in the central, periportal, or medial area. ${ }^{1}$ Peliosis hepatis differs from sinusoidal dilatation by the formation of blood lakes without preferential location. ${ }^{1}$ HSD can be encountered in three different situations. Firstly, sinusoidal dilatation is commonly found in the vicinity of hepatic tumours or in patients with heart failure, hepatic venous outflow block, veno-occlusive disease, granulomatous disorders, infectious conditions, or infiltration of sinusoids by various types of benign or malignant cells. $^{2-8}$ Secondly, sinusoidal dilatation is common in the clinicopathological entity non-cirrhotic intrahepatic portal hypertension which consists of various types of architectural alterations. These alterations include nodular regenerative hyperplasia, perisinusoidal fibrosis, hepatoportal sclerosis, or incomplete septal cirrhosis. ${ }^{9-11}$ These architectural alterations have been related to several causal factors, including xenobiotics (thorium salts, arsenicals, vinyl chloride, vitamin
A, or azathioprine $)^{12}$ and thrombophilia. ${ }^{11}$ All of these factors have been postulated to act by inducing portal or sinusoidal obstruction. ${ }^{11}$ Thirdly, exceptional sinusoidal dilatation is an isolated finding of unclear origin. ${ }^{2}$ It is then referred to as idiopathic, although a role for oral contraceptives has been debated. ${ }^{2}$ Irrespective of the three situations above, a role for activated perisinusoidal cells can be speculated because of their contractile properties which may explain sinusoidal stenoses and dilatation. ${ }^{13} 14$

The aims of this study were: (a) to assess whether the prothrombotic disorders that have been implicated in noncirrhotic intrahepatic portal hypertension are also implicated in isolated HSD and (b) to investigate whether perisinusoidal cell changes could be involved in pure idiopathic HSD.

\section{PATIENTS AND METHODS \\ Patients}

All patients referred between 1993 and 2002 to the hepatology unit of Beaujon Hospital for unexplained hepatic test abnormalities and in whom liver biopsy showed pure idiopathic HSD at histological analysis were considered. Pure idiopathic HSD was defined as isolated HSD without fibrosis, inflammation, congestion, or architectural changes (see histological analyses below) diagnosed in patients without the following conditions: heart or blood disorders; granulomatous, malignant, inflammatory, or infectious diseases; or obstructed hepatic or portal veins. Search for these associated conditions was based on a complete medical history and physical examination, chest radiograph, blood cell counts, erythrocyte sedimentation rate and $\mathrm{C}$ reactive protein determination, complete ultrasound or computed tomography scan of the abdomen, and liver histological analysis. All patients underwent Doppler ultrasound for evaluation of hepatic thrombosis.

All cases were obtained from a pathological database. Between 1993 and 2002, 42 patients were found to have HSD on liver biopsy in the absence of the following conditions: heart disorders, malignant diseases, or obstructed hepatic veins. Eleven of 42 patients fulfilled the inclusion criteria of pure idiopathic HSD. After giving written informed consent, all patients were investigated for a prothrombotic state.

\section{Investigations for prothrombotic disorders}

All patients were routinely investigated for a prothrombotic state. Lupus anticoagulant was investigated as previously described. ${ }^{15} \mathrm{~A}$ commercial kit was used to assay antiphospholipid antibodies of IgG and IgM types (Biogenic, Montpellier, France). Antithrombin and protein C functional deficiencies, and total and/or free protein $S$ antigenic

Abbreviations: HSD, hepatic sinusoidal dilatation; $\alpha$-SMA, $\alpha$-smooth muscle actin 
Table 1 Main characteristics in 11 consecutive patients with idiopathic pure hepatic sinusoidal dilatation

\begin{tabular}{|c|c|c|c|c|c|c|c|c|c|c|}
\hline $\begin{array}{l}\text { Patient No } \\
\text { (sex/age) }\end{array}$ & $\begin{array}{l}\text { Specific } \\
\text { features }\end{array}$ & Medications & $\begin{array}{l}\text { ALT } \\
(\times \text { ULN })\end{array}$ & $\begin{array}{l}\text { GGT } \\
(\times \text { ULN })\end{array}$ & $\begin{array}{l}\text { AP } \\
(\times \text { ULN })\end{array}$ & LA & $\begin{array}{l}\text { Anticardiolipin } \\
\text { antibodies* }^{*}\end{array}$ & $\begin{array}{l}\text { ANA } † \\
\text { (titre) }\end{array}$ & $\begin{array}{l}\text { Sinusoidal } \\
\text { dilatation }\end{array}$ & $\begin{array}{l}\text { Activated } \\
\text { perisinusoidal } \\
\text { cells }\end{array}$ \\
\hline $1(F / 31)$ & $\begin{array}{l}2 \text { previous early } \\
\text { abortions. } \\
\text { Thrombocytopenia. } \\
\text { Familial } \\
\text { thrombophilia }\end{array}$ & None & 3 & 8 & 3.5 & + & $\begin{array}{l}\lg G 52 \text { and } 45 \mathrm{GPL} \\
\lg M<10 \mathrm{MPL}\end{array}$ & $1 / 500$ & Moderate & Absent \\
\hline $2(F / 29)$ & Unremarkable & None & 1.5 & 4 & 3.5 & + & $\begin{array}{l}\lg G 40 \text { and } 45 \mathrm{GPL} \\
\lg M<10 \mathrm{MPL}\end{array}$ & $1 / 500$ & Marked & Present \\
\hline $3(M / 39)$ & Unremarkable & None & 3.2 & 2.5 & 4.1 & + & $\begin{array}{l}\operatorname{lgG} 40 \text { and } 45 \mathrm{GPL} \\
\lg M<10 \mathrm{MPL}\end{array}$ & $1 / 250$ & Moderate & Absent \\
\hline $4(\mathrm{~F} / 52)$ & Unremarkable & None & 3.3 & 3.8 & 5 & + & $\begin{array}{l}\operatorname{lgG}<10 \mathrm{GPL} \\
\operatorname{lgM} 15 \text { and } 22 \mathrm{MPL}\end{array}$ & Neg & Marked & Present \\
\hline $5(F / 36)$ & $\begin{array}{l}\text { Occult } \\
\text { myeloproliferative } \\
\text { disorder }\end{array}$ & $\begin{array}{l}\text { Oestro- } \\
\text { progestatives }\end{array}$ & 2 & 5 & 2.4 & Neg & Neg & Neg & Moderate & Absent \\
\hline $6(F / 25)$ & Unremarkable & $\begin{array}{l}\text { Oestro- } \\
\text { progestatives }\end{array}$ & 2 & 6.3 & 3.3 & Neg & Neg & Neg & Marked & Present \\
\hline $7(M / 60)$ & Unremarkable & None & 2.1 & 2 & 3 & Neg & $\mathrm{Neg}$ & Neg & Moderate & Absent \\
\hline $8(F / 20)$ & Unremarkable & None & 3 & 7 & 3.1 & Neg & $\mathrm{Neg}$ & Neg & Marked & Present \\
\hline 9 (F/47) & Unremarkable & None & 1 & 3 & 3 & Neg & Neg & Neg & Moderate & Absent \\
\hline $10(F / 32)$ & Unremarkable & None & 3.1 & 7.3 & 2 & Neg & Neg & Neg & Marked & Present \\
\hline $11(F / 31)$ & Unremarkable & $\begin{array}{l}\text { Oestro- } \\
\text { progestatives }\end{array}$ & 1 & 4 & 3 & Neg & Neg & Neg & Marked & Present \\
\hline
\end{tabular}

deficiencies were assessed using commercial kits (Diagnostica Stago, Asnières, France). Genetic analyses were performed according to previously reported methods for G1691A factor V and G202110A prothrombin. ${ }^{16}{ }^{17}$ Plasma total homocysteine levels were measured using high performance liquid chromatography with fluorometric detection. ${ }^{18}$ Endogenous erythroid colonies and total red cells were assessed as previously reported ${ }^{19}$ in nine patients (patient Nos 1, 2, 3, 5, 6, 7, 8, 9, and 10) to exclude an occult myeloproliferative disorder. Patient Nos 4 and 11 refused bone marrow aspiration. Evaluation of the CD55-CD59 cluster was performed to rule out paroxysmal nocturnal haemoglobinuria. ${ }^{20}$

\section{Histological analyses}

Liver biopsy slides were reviewed by the same pathologist. Pure sinusoidal dilatation was defined as sinusoidal spaces more than one hepatocyte plate in width without any other histological abnormality in haematoxylin-eosin stained slides. The degree of dilatation was graded as moderate when sinusoidal spaces were at most two plates wide, and marked beyond this width. Gordon Sweet and Masson stains were used to exclude cases with perisinusoidal fibrosis. Immunohistochemical staining was carried out to detect activated perisinusoidal cells, using the three step immunoperoxidase technique without pretreatment. We used the following primary antibodies: monoclonal anti- $\alpha$-smooth muscle actin ( $\alpha$-SMA) (1A4, dilution 1/25; Dako, Glostrup, Denmark) and anti-CD34 (QBEND 10, dilution 1/50; Immunotech, Marseille, France). ${ }^{21}$ Using our procedure, no $\alpha$-SMA positive perisinusoidal cells were detectable in normal adult liver (in revascularisation biopsy at transplantation). The presence of activated perisinusoidal cells was based on detection of $\alpha$-SMA positive and CD34 negative cells in Disse spaces.

\section{RESULTS}

Eleven patients fulfilling the inclusion criteria were enrolled into the study. There were two male and nine female patients (median age 37 years (range 19-60)). All patients had a normal clinical examination and presented with persistently abnormal liver function tests (mainly raised gamma glutamyl transferase), which led to liver biopsy.

Associated conditions are presented in table 1. Among 11 patients, associated conditions were prothrombotic disorders $(n=5)$ and oral contraceptive use $(n=3)$. Prothrombotic disorders were polycythemia vera $(\mathrm{n}=1)$ and anticardiolipin antibodies combined with lupus anticoagulant $(n=4)$. No genetic thrombophilia factor was found. All four patients had lupus anticoagulant and three had antinuclear factors and high serum levels of anticardiolipin antibodies at repeated testing. None had clinical or laboratory evidence of connective tissue disease. Oral contraceptive use was the sole associated condition in one patient. No associated condition was found in four patients.

Histological findings are presented in table 1 and are illustrated in fig 1. Marked sinusoidal dilatation was encountered in six of 11 biopsies (54\%), including two patients with antiphospholipid antibodies. Positive alpha actin staining in perisinusoidal cells was demonstrated in six cases, all with marked sinusoidal dilatation. On Doppler ultrasound and histological analysis, there was no evidence of intrahepatic or extrahepatic thrombosis in any patient.

Patient No 1, with a history of two abortions and familial thromboembolic disease, was given long term oral anticoagulation. During a mean follow up of four years (range 27 ), no change in clinical, laboratory, or Doppler ultrasound features were observed in any of the 11 patients.

\section{DISCUSSION}

This study indicates that idiopathic pure HSD is associated with immunological features of antiphospholipid syndrome. ${ }^{22}$ In contrast with other primary vascular disorders of the liver, ${ }^{11}{ }^{23}$ HSD was associated with only one case of occult primary myeloproliferative disorder and no cases of heritable thrombophilia. Antiphospholipid syndrome has not yet been reported to cause sinusoidal dilatation. Thus the fact that antiphospholipid antibodies accounted for four out of five 

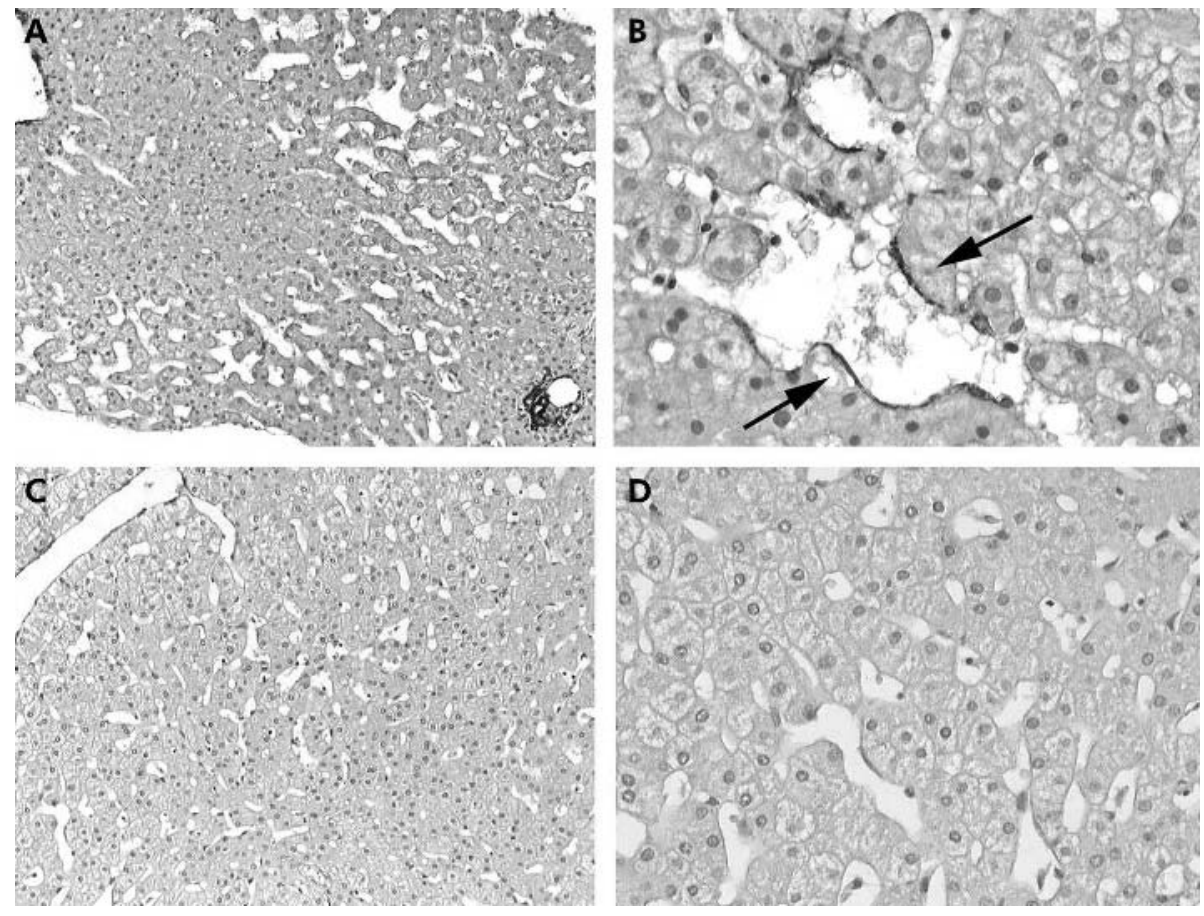

Figure 1 Marked sinusoidal dilatation, prominent in the mediolobular zone of the lobule (zone 2) $(A, \times 100)$ with detection of $\alpha$-smooth muscle actin positive perisinusoidal cells $(B$, arrows, $\times 250)$. Moderate sinusoidal dilatation in zones 2 and $3(C, \times 100)$, with no $\alpha$-smooth muscle actin positive cells detected $(D, \times 250)$.

identified prothrombotic disorders is an important finding of this study. The prevalence of antiphospholipid antibodies in this cohort was $36 \%$ (four of 11 patients) compared with a reported maximum of 5\% among young apparently healthy control subjects. ${ }^{24}$ At repeat testing, all four patients had the lupus anticoagulant (including three with high serum levels of antinuclear factors and anticardiolipin antibodies), a feature that is associated with thrombophilia. ${ }^{25}$ However, none of our patients had evidence of present or past thrombosis. None strictly fulfilled the criteria for antiphospholipid syndrome. ${ }^{22}$ Except for autoantibodies, there was no evidence of a connective tissue disease. Oral contraceptive use, another potential cause of sinusoidal dilatation, ${ }^{12}$ was present in only three patients in this cohort, none of whom had antiphospholipid antibodies. This fact argues against a prominent role of oral contraceptives. Thus persistently abnormal liver biochemistry was the only clue to HSD and, eventually, to the presence of the immunological anomalies. Therefore, finding idiopathic pure HSD in a liver biopsy specimen should prompt the search for antiphospholipid antibodies. Furthermore, in patients with antiphospholipid antibodies and abnormal liver function tests, sinusoidal dilatation should be considered.

Contrasting with the prothrombotic disorders documented in five patients, HSD could not be readily explained by microvascular thromboses. As reviewed elsewhere, ${ }^{13}{ }^{14}$ perisinusoidal cells can modulate sinusoidal calibre; they are activated by thrombin and, when activated, contribute to hepatic fibrogenesis. Indeed, perisinusoidal fibrosis and sinusoidal dilatation are frequently found in non-cirrhotic intrahepatic portal hypertension associated with prothrombotic disorders. ${ }^{11}$ However, in this cohort, activated perisinusoidal cells were found only around markedly dilated sinusoids, suggesting a consequence rather than a cause of HSD. Thus the mechanism leading to HSD, whether related or not to antiphospholipid antibodies, remains elusive. Although unproven, sinusoidal outflow obstruction is a likely mechanism, at least in cases where a prothrombotic disorder is found. Alternatively, it can be hypothesised that direct injury to hepatic endothelial cell by antiphospholipid antibodies may contribute to the sinusoidal lining disruption leading to the formation of HSD. Along this line, recent studies demonstrated that vascular endothelial cell injury plays a major role in the pathogenesis of antiphospholipid syndrome..$^{26-28}$

Whether the entity combining idiopathic pure HSD and antiphospholipid antibodies can be regarded as a variant of antiphospholipid syndrome is relevant for issues of outcome and therapy. Over a 2-5 year follow up, all four patients with antiphospholipid antibodies have remained asymptomatic with stable liver biochemistry. The benefit of anticoagulation in patient No 1 (with a history of two abortions, low platelet counts, and a familial history of thrombophilia) remains unproved. However, antiphospholipid syndrome can cause severe vascular disorders of the liver, including non-cirrhotic intrahepatic portal hypertension, ${ }^{29}$ and portal vein or hepatic vein thrombosis. ${ }^{23}$ Whether idiopathic pure HSD associated with antiphospholipid antibodies heralds the development of these severe complications requires further clarification. At present, anticoagulation cannot be recommended as there was no evidence of vascular obstruction or thrombosis, and short term outcome was excellent.

\section{Authors' affiliations}

D Saadoun, V Mallet, B Condat, D Valla, Service d'Hépatologie and INSERM U 481, Hôpital Beaujon (Assistance Publique-Hôpitaux de Paris, Université Paris 7), Clichy, France

D Cazals-Hatem, Service d'Anatomie et de Cytologie Pathologiques, Hôpital Beaujon (Assistance Publique-Hôpitaux de Paris, Université Paris 7), Clichy, France

M-H Denninger, L Boudaoud, B-N Pham, Service d'Hématologie et d'Immunologie, Hôpital Beaujon (Assistance Publique-Hôpitaux de Paris, Université Paris 7), Clichy, France

J Brière, Service d'Hématologie Clinique, Hôpital Beaujon (Assistance Publique-Hôpitaux de Paris, Université Paris 7), Clichy, France 
Correspondence to: Professor D Valla, Service d'Hépatologie, Hôpital Beaujon, 92118 Clichy, France; dominique.valla@bjn.ap-hop-paris.fr

Revised version received 5 February 2004

Accepted for publication 30 March 2004

\section{REFERENCES}

1 Degott C, Potet F. Peliosis hepatitis and sinusoidal dilatation. Arch Anat Cytol Pathol 1984;32:296-300.

2 Bruguera $M$, Aranguibel F, Ros $E$, et al. Incidence and clinical significance of sinusoidal dilatation in liver biopsies. Gastroenterology 1978;75:474-8.

3 Capron JP, Lemay JL, Gontier MF, et al. Hepatic sinusoidal dilatation in Crohn's disease. Scand J Gastroenterol 1979;14:987-92.

4 Laffon A, Moreno A, Gutierrez-Bucero A, et al. Hepatic sinusoidal dilatation in rheumatoid arthritis. J Clin Gastoenterol 1989:11:653-7.

5 Aoyagi T, Mori I, Ueyama Y, et al. Sinusoidal dilatation of the liver as a paraneoplastic manifestation of renal cell carcinoma. Hum Pathol 1989;20:1193-7.

6 Bruguera M, Caballero T, Carreras $E$, et al. Hepatic sinusoidal dilatation in Hodgkin's disease. Liver 1987;7:76-80.

7 Balazs M. Sinusoidal dilatation of the liver in patients on oral contraceptives. Electron microscopical study of 14 cases. Exp Pathol 1988;35:231-7.

8 Scoazec JY, Marche C, Girard PM, et al. Peliosis hepatis and sinusoidal dilatation during infection by the human immunodeficiency virus (HIV). An ultrastructural study. Am J Pathol 1988;131:38-47.

9 Bilodeau M, Aubry MC, Houle R, et al. Evaluation of hepatocyte injury following partial ligation of the left portal vein. J Hepatol 1999;30:29-37.

10 Ludwig J, Hashimoto $\mathrm{E}$, Obata $\mathrm{H}$, et al. Idiopathic portal hypertension. Hepatology 1993;17:1157-62

11 Hillaire S, Bonte E, Deninger MH, et al. Idiopathic non-cirrhotic intrahepatic portal hypertension in the West: a reevaluation in 28 patients. Gut 2002;51:275-80

12 Zafrani ES, Pinaudeau Y, Dhumeaux D. Drug-induced vascular lesions of the liver. Arch Intern Med 1983;143:495-502.

13 Rockey DC. Hepatic blood flow regulation by stellate cells in normal and injured liver. Semin Liver Dis 2001;21:337-49.

14 Cassiman D, Roskams T. Beauty is in the eye of the beholder: emerging concepts and piffalls in hepatic stellate cell research. J Hepatol 2002;37:527.

15 Rosner E, Pauzner R, Lusky A, et al. Detection and quantitative evaluation of lupus circulating anticoagulant activity. Thromb Haemost 1987;57:144-8.
16 Bertina RM, Koeleman RPC, Koster T, et al. Mutation in blood coagulation factor $\mathrm{V}$ associated with resistance to activated protein $\mathrm{C}$. Nature 1994;369:64-7.

17 Poort SR, Rosendaal FR, Reitsma PH, et al. A common genetic variation in the $3^{\prime}$-untranslated region of the prothrombin gene is associated with elevated plasma prothrombin levels and an increase in venous thrombosis. Blood 1996;88:3698-703.

18 Araki A Sako Y. Determination of free and total homocysteine in human plasma by high-performance liquid chromatography with fluorescence detection. J Chromatogr 1987;422:43-52.

19 Berlin NI. Classification of the polycythemias and initial clinical features in polycythemia vera. In: Wasserman LR, Berk PD, Berlin NI, eds. Polycythemia vera and the myeloproliferative disorders. Philadelphia: WB Saunders Company, 1995:22-30.

20 Schubert J, Alvarado M, Uciechowski P, et al. Diagnosis of paroxysmal nocturnal hemoglobinuria using immunophenotyping of peripheral blood cells. Br J Haematol 1991;79:487-91.

21 Nouchi T, Tanaka Y, Tsukada T, et al. Appearance of alpha-smooth-actinpositive cells in hepatic fibrosis. Liver 1991;11:100-5.

22 Levine JS, Branch DW, Rauch J. The antiphospholipid syndrome. N Engl J Med 2002;346:752-63.

23 Denninger MH, Chait $Y$, Casadevall N, et al. Cause of portal or hepatic venous thrombosis in adults: The role of multiple concurrent factors. Hepatology 2000;31:587-91.

24 Petri M. Epidemiology of the antiphospholipid antibody syndrome. J Autoimmun 2000;15:145-51

25 Wahl DG, Guillemin F, de Maistre E, et al. Meta-analysis of the risk of venous thrombosis in individuals with antiphospholipid antibodies without underlying autoimmune disease or previous thrombosis. Lupus 1998;7:15-22.

26 Burcoglu-O'ral A, Erkan D, Asherson RA. Treatment of catastrophic antiphospholipid syndrome (CAPS) with defibrotide, a proposed vascular endothelial cell modulator. J Rheumatol 2002;29:2006-11.

27 Meroni PL, Raschi E, Testoni C, et al. Statins prevent endothelial cell activation induced by antiphospholipid anttibodies: effect on the proadhesive and proinflammatory phenotype. Arthritis Rheum 2001;44:2870-8.

28 Roubey RAS. New approachs to prevention of thrombosis in the antiphospholipid syndrome: hopes, trials and tribulations. Arthritis Rheum 2003;41:3004-8.

29 Perez-Ruiz F, Zea-Mendoza AC. Nodular regenerative hyperplasia of the liver and antiphospholipid antibodies. J Clin Gastroenterol 1998;27:90-1. 